\title{
Development of a Multi-criteria Decision Model for Nigerian Refinery Bottlenecks
}

\author{
T. B. Adeleke, R. O. Edokpia, M. K. Onifade, and N. B. Chime
}

\begin{abstract}
Production systems are continually surrounded by bottleneck problems that limit their overall performances. The petroleum industry today faces a lot of challenges which border on production bottlenecks that tend to limit production throughput and hence output. The purpose of this study is to provide a decision support strategy for refinery operators and mangers as well as other stakeholders. The multi-criteria models used were the Analytical Hierarchy Process (AHP) and the Test of Preference by Similarity to Ideal Solution (TOPSIS). A 9point saaty scale and 10-point linguistic scale questionnaires were used to elicit responses from experts in the refinery. The statistical computations with the Multi-criteria Decision Model were carried out with the aid of (AHP -OS) BPMSG software on nine criteria which are bottleneck variables which impact on refinery operations and the comparison was made by nine decision makers who are refinery experts while TOPSIS was used for alternatives selection. The result of the AHP showed the contributing weights of individual criterion with "Government Interference" ranking first, exerting a weight of $19.84 \%$. The result also generated a normalized total matrix which is approximately one (1), consistency index of 0.09694 and a consistency ratio of 0.06685 which is within acceptable limit and finally from TOPSIS modeling, "Denationalization" with the highest value of 0.7598 was found to be closest to the ideal solution for the optimal refinery performance. This study has developed a multi-criteria decision model for selecting the best alternative for optimal performance based on inputs from experts and this provides a veritable framework that serves as a decision support strategy for policy makers and stakeholders in the operations of the refinery.
\end{abstract}

Index Terms - AHP, Bottlenecks, Modeling, Refineries, TOPSIS.

\section{INTRODUCTION}

The decision making process for the selection of an appropriate strategy for the optimization of petroleum refinery operations, is a multi-criteria decision making problem [1]. Decision makers in petroleum refineries, sometimes execute poor decisions in a fuzzy situation, because of many conflicting criteria that need to be considered [2]. Poor decisions can be as a result of incomplete information about an alternative strategy for bottleneck prevention, control and mitigation. Decision makers' perspective about available information determines the basis for making robust decisions in regards to their operations [3]. Furthermore, lack of resolution in the collective knowledge of decision makers about a system problem can result in a

Submitted on June 07, 2021.

Published on July 29, 2021.

T. B. Adeleke, Department of Production Engineering, University of Benin, Benin City, Edo State, Nigeria.

(e-mail: tunde.adeleke@ ${ }^{@}$ eng.uniben.edu)

R. O. Edokpia, Department of Production Engineering, University of Benin, Benin City, Edo State, Nigeria.

(e-mail: ralph.edokpia ${ }^{@}$ uniben.edu) bias outcome or conflict of interest in a decision process. Therefore, it is vital in a decision making process for decision makers to consider data in the form of a qualitative assessment or quantitative assessment or both [4]. According to [5], [6] and [7], Nigeria is the seventh world producer and sixth world exporter of crude oil. On the domestic economy, the petroleum sector generates over $90 \%$ of the country's foreign exchange earnings and provides employment in various forms to Nigerians.

Petroleum Refineries are complex multifaceted systems that perform multiple phase operations. Bottlenecks in the refineries lead to the disruption of refinery operations which result in production loss and time wastage. A lot of factors have affected the Nigerian refineries from producing optimally and the collective and the individual interplay among these factors have not been understood as a resourceful modeling approach to study these bottlenecks in the refineries have been absent [8]. This study seeks to apply a multi-criteria decision approach in modeling the relevant disruption factors that impact Nigerian Refinery operations. This is to help develop a decision strategy that provides a veritable framework that can nudge the refineries to a decent situation through policy and operational decision making.

\section{METHODOLOGY}

\section{A. Analytical Hierarchy Process}

In the analytic hierarchy process, we defined a set of criteria to do pairwise comparisons and find the weights of criteria or decision alternatives.

Nine (9) criteria were chosen for the study, these are shown in Table I.

\begin{tabular}{ccc} 
& TABLE I: CRITERIA IDENTIFICATION & \\
\hline Criteria Index & Criteria Description & Notation \\
\hline C1 & Aging Infrastructure & AI \\
C2 & Petroleum Industry Bill & PIB \\
C3 & Foreign Investors & FI \\
C4 & Turn Around & TAM \\
& Maintenance & \\
C5 & Pressure Groups and & PGU \\
C6 & Unionization & OR \\
C7 & OPEC Regulations & MRG \\
C8 & Multiple Regulators & GI \\
C9 & Government Interference & MR \\
\hline
\end{tabular}

M. K. Onifade, Department of Management Technology, Bells University of Technology, Ota, Ogun State, Nigeria.

(e-mail: morakinyo.onifade ${ }^{\circledR}$ yahoo.com)

N. B. Chime, Department of Production Engineering, University of Benin, Benin City, Edo State, Nigeria.

(e-mail: chime.benjamin ${ }^{\circledR}$ gmail.com) 


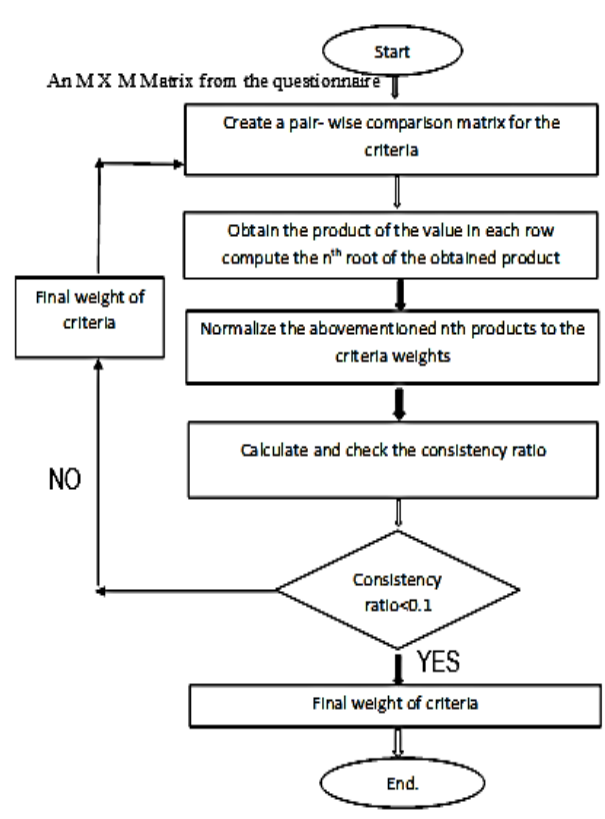

Fig. 1. Flowchart of the AHP.

\section{B. TOPSIS Mathematical Model}

$r_{i j}=\frac{x_{i j}}{\sqrt{\sum_{k=1}^{m} x_{k j}^{2}}}, i=1,2, \ldots, m, j=1,2, \ldots, n$

$t_{i j}=r_{i j} . w_{j}, \mathrm{i}=1,2, \ldots, \mathrm{m}, \mathrm{j}=1,2, \ldots$,

$A_{w}=$

$\left\{\left(\max \left(t_{i j} \mid i=1,2, \ldots, m\right) \mid j \in J_{-}\right),\left(\min \left(t_{i j} \mid i=1,2, \ldots, m\right) \mid j \in\right.\right.$ $\left\{t_{w j} \mid j=1,2, \ldots, n\right)$

$A_{b}=$

$\left\{\left(\min \left(t_{i j} \mid i=1,2, \ldots, m\right) \mid j \in J_{-}\right),\left(\max \left(t_{i j} \mid i=1,2, \ldots, m\right) \mid j \in J_{+}\right)\right\} \equiv$

$\left\{t_{b j} \mid j=1,2, \ldots n\right\}$,

$d_{i w}=\sqrt{\sum_{j=1}^{n}\left(t_{i j}-t_{w j}\right)^{2}}, 1,2, \ldots, m$

and the distance between the alternative and the best condition $A_{b}$.

$$
\begin{aligned}
& d_{i b}=\sqrt{\sum_{j=1}^{n}\left(t_{i j}-t_{b j}\right)^{2}}, 1,2, \ldots, m, \\
& s_{i w}=\frac{d_{i w}}{d_{i w}+d_{i b}}, 0 \leq s_{i w} \leq 1, i=1,2, \ldots, m
\end{aligned}
$$

$s_{i w}=1$ if and only if the alternative solution has the best condition; and $s_{i w}=0$ if and only if the alternative solution has the worst condition.

Rank the alternatives according to $s_{i w}(i=1,2, \ldots, m)$

\section{RESULTS AND DISCUSSION}

The nine criteria were analysed using an MCDM tool AHP, and the weight of each criterion and principal eigen values were determined and presented. A one-time explanation

\begin{tabular}{|c|c|c|c|c|c|c|c|c|c|}
\hline & $A I$ & $P I B$ & $F I$ & $T A M$ & $P G U$ & $O R$ & $M R G$ & $G I$ & $M R$ \\
\hline$A I$ & 1 & 2 & 1 & 2 & 4 & 1 & 2 & 1 & 3 \\
\hline$P I B$ & 0.5 & 1 & 3 & 2 & 4 & 2 & 2 & 2 & 3 \\
\hline$F I$ & 1 & 0.33 & 1 & 1 & 1 & 1 & 1 & 1 & 1 \\
\hline TAM & 0.5 & 0.5 & 1 & 1 & 2 & 2 & 1 & 1 & 3 \\
\hline$P G U$ & 0.25 & 0.25 & 1 & 0.5 & 1 & 0.33 & 1 & 1 & 1 \\
\hline$O R$ & 1 & 0.5 & 1 & 0.5 & 3 & 1 & 3 & 1 & 2 \\
\hline$M R G$ & 0.5 & 0.5 & 1 & 1 & 1 & 0.33 & 1 & 1 & 1 \\
\hline$G I$ & 1 & 0.5 & 1 & 1 & 1 & 1 & 1 & 1 & 5 \\
\hline$M R$ & 0.33 & 0.33 & 1 & 0.33 & 1 & 0.5 & 1 & 0.2 & 1 \\
\hline & $A I$ & $P I B$ & $F I$ & $T A M$ & $P G U$ & $O R$ & $M R G$ & GI & $M R$ \\
\hline$A I$ & 1 & 3 & 1 & 2 & 5 & 4 & 2 & 1 & 1 \\
\hline$P I B$ & 0.33 & 1 & 0.5 & 3 & 4 & 3 & 3 & 0.5 & 1 \\
\hline$F I$ & 1 & 2 & 1 & 1 & 2 & 3 & 2 & 1 & 1 \\
\hline$T A M$ & 0.5 & 0.33 & 1 & 1 & 4 & 3 & 4 & 0.33 & 1 \\
\hline$P G U$ & 0.2 & 0.25 & 0.5 & 0.25 & 1 & 0.25 & 0.33 & 0.2 & 0.25 \\
\hline$O R$ & 0.25 & 0.33 & 0.33 & 0.33 & 4 & 1 & 3 & 0.25 & 2 \\
\hline$M R G$ & 0.5 & 0.33 & 0.5 & 0.25 & 3 & 0.33 & 1 & 0.167 & 1 \\
\hline$G I$ & 1 & 2 & 1 & 3 & 5 & 4 & 6 & 1 & 5 \\
\hline$M R$ & 1 & 1 & 1 & 1 & 4 & 0.5 & 1 & 0.2 & 1 \\
\hline
\end{tabular}
rendered.
$D M_{1} D M_{2} D_{3} D M_{4} D M_{3} D M_{6} D M_{2} D M_{3} D M_{3}$ Rowis

$\begin{array}{lllllllllll}\text { AI } & 17.4 & 12.9 & 17.2 & 15.6 & 15.6 & 17.8 & 16.2 & 16.2 & 17.3 & 16.20\end{array}$

$\begin{array}{lllllllllll}P I B & 18.9 & 13.4 & 14.1 & 13.9 & 14.1 & 14.1 & 13.6 & 13.9 & 12.4 & 14.30\end{array}$

$\begin{array}{lllllllllll}\text { FI } & 9.1 & 9.4 & 9.7 & 9.5 & 9.5 & 10.7 & 10.7 & 12.3 & 13.4 & 10.50\end{array}$

$\begin{array}{lllllllllll}\text { TAM } & 11.5 & 11.2 & 11.2 & 10.1 & 11.6 & 10.8 & 10.5 & 11.3 & 10.6 & 10.98\end{array}$

$\begin{array}{lllllllllll}P G U & 6.1 & 5.3 & 5.2 & 4.6 & 4.5 & 3.2 & 2.1 & 2.4 & 2.9 & 4.03\end{array}$

$\begin{array}{llllllllll}\left.\left.j \in g_{+}\right)\right\} & 13.8 & 10.5 & 11.4 & 10.6 & 9.6 & 9.5 & 8.8 & 7.3 & 10.41\end{array}$

$\begin{array}{lllllllllll}\text { MRG } & 7.7 & 7.4 & 7.4 & 6.5 & 6.2 & 5.8 & 5.5 & 5.4 & 5.0 & 6.32\end{array}$

$\begin{array}{lllllllllll}\text { GI } & 11.7 & 19.4 & 16.8 & 20.2 & 19.9 & 20.7 & 25.2 & 22.2 & 22.5 & 19.84\end{array}$

$\begin{array}{lllllllllll}\text { MR } & 5.5 & 7.2 & 7.9 & 8.1 & 7.9 & 7.4 & 6.6 & 7.5 & 8.6 & 7.41\end{array}$

TABLE II: CRITERIA WEIGHT RANKING

\begin{tabular}{cccc}
\hline Notation & Criteria & Weight & Rank \\
\hline$C_{1}$ & AI & 16.20 & 2 \\
$C_{2}$ & PIB & 14.30 & 3 \\
$C_{3}$ & FI & 10.50 & 5 \\
$C_{4}$ & TAM & 10.98 & 4 \\
$C_{5}$ & PGU & 4.03 & 9 \\
$C_{6}$ & OR & 10.41 & 6 \\
$C_{7}$ & MRG & 6.32 & 8 \\
$C_{8}$ & GI & 19.84 & 1 \\
$C_{9}$ & MR & 7.41 & 7 \\
\hline
\end{tabular}

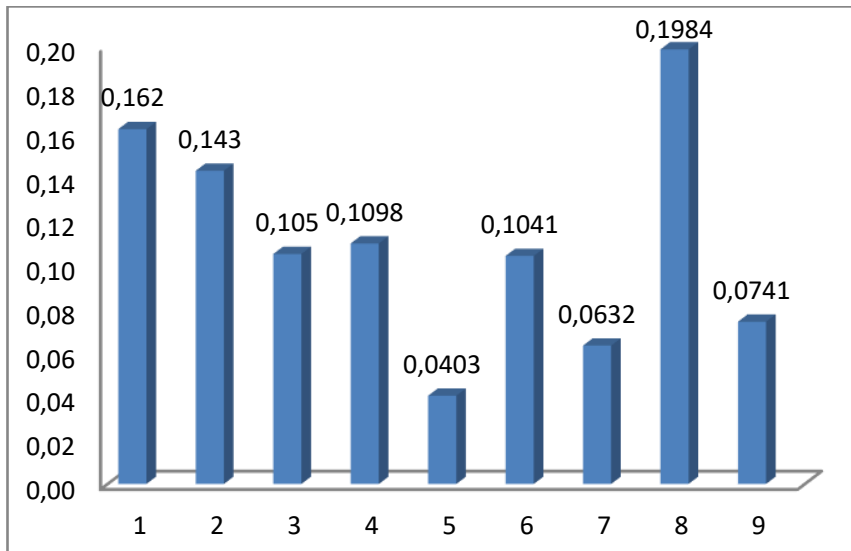

Fig. 2. Clustered Column of Bottleneck criteria. 
TABLE III: SUMMARY OF EIGENVALUE FOR CONSISTENCY ANALYSIS

\begin{tabular}{cc}
\hline Decision Makers & $\begin{array}{c}\text { Principal Eigenvalue } \\
\lambda(\max )\end{array}$ \\
\hline DM1 & 9.633 \\
DM2 & 9.906 \\
DM3 & 9.600 \\
DM4 & 9.775 \\
DM5 & 9.744 \\
DM6 & 9.818 \\
DM7 & 9.589 \\
DM8 & 9.853 \\
DM9 & 10.062 \\
Mean Decision & 9.775 \\
Total $\lambda(\max )$ & 87.980 \\
\hline
\end{tabular}

From Table III above, $\lambda(\max )=87.980$. But,

$$
C R=\left(\frac{C I}{R I}\right)
$$

$C I=\frac{\frac{\lambda \max }{n}-n}{n-1}$

$C R=\frac{0.09694}{1.45} * 100 \%=6.68 \%$

\section{A. Results from Topsis}

The matrix $\left(x_{i j}\right) m \times n$ is normalized to form the matrix $R=\left(r_{i j}\right) m \times n$ using the normalization method.

From the results of calculated alternatives closeness index value, alternative 5 has the maximum closeness index according to the ranking in Table VIII. The ranking is $A_{5}>A_{2}>A_{4}>A_{1}>A_{3}$. According to the result, alternative $A_{5}$ is chosen as the best alternative among the considered alternatives.
Based on the above condition $0 \leq \mathrm{Ci} \leq 1$, all the alternatives fall in between the range. The above analysis shows that Denationalization is the best decision strategy because it is closest to the ideal solution with a closeness figure of 0.7598 , so close to 1 which is the ideal solution. The best decision strategy gives lesser cost and waste which in turn increase the performance (productivity) of the refineries.

TABLE IV: DECISION MATRIX CONSISTING OF M ALTERNATIVES AND N CRITERIA

\begin{tabular}{cccccccccc}
\hline $\begin{array}{c}\text { Decision } \\
\begin{array}{c}\text { Alternatives } \\
\text { for Optimal } \\
\text { Performance }\end{array}\end{array}$ & $\mathrm{C} 1$ & $\mathrm{C} 2$ & $\mathrm{C} 3$ & $\mathrm{C} 4$ & $\mathrm{C} 5$ & $\mathrm{C} 6$ & $\mathrm{C} 7$ & $\mathrm{C} 8$ & $\mathrm{C} 9$ \\
\hline$A_{1}$ & 9 & 7 & 9 & 10 & 9 & 9 & 8 & 3 & 9 \\
$A_{2}$ & 7 & 9 & 4 & 9 & 5 & 7 & 4 & 5 & 9 \\
$A_{3}$ & 8 & 5 & 6 & 3 & 4 & 5 & 4 & 4 & 6 \\
$A_{4}$ & 5 & 7 & 9 & 8 & 6 & 7 & 9 & 5 & 8 \\
$A_{5}$ & 3 & 9 & 7 & 9 & 9 & 8 & 5 & 7 & 9 \\
\hline
\end{tabular}

\begin{tabular}{ccc}
\multicolumn{3}{c}{ TABLE VIII: RANKED ALTERNATIVES } \\
\hline Alternative & $\begin{array}{c}\text { Closeness to the ideal } \\
\text { solution }\end{array}$ & Rank \\
\hline$A_{1}$ & 0.4950 & $\mathbf{4}$ \\
$A_{2}$ & 0.6061 & $\mathbf{2}$ \\
$A_{3}$ & 0.4235 & $\mathbf{5}$ \\
$A_{4}$ & 0.5939 & $\mathbf{3}$ \\
$A_{5}$ & 0.7598 & $\mathbf{1}$ \\
\hline
\end{tabular}

TABLE IX: ALTERNATIVES CONNOTATION

\begin{tabular}{cc}
\hline$A_{1}$ & Maintenance Methodology \\
$A_{2}$ & Modular \& Conventional Refineries \\
$A_{3}$ & OPEC Guidelines \\
$A_{4}$ & Manageering \\
$A_{5}$ & Denationalization \\
\hline
\end{tabular}

TABLE V: TOPSIS VECTOR NORMALIZATION

\begin{tabular}{|c|c|c|c|c|c|c|c|c|c|}
\hline \multicolumn{10}{|l|}{$x_{i}=\frac{x_{i j}}{1}$} \\
\hline$r_{i j}=\frac{\sqrt{\sum_{k=1}^{m} x_{k j}^{2}}}{\sqrt{n^{2}}}$ & $\mathrm{C} 1$ & $\mathrm{C} 2$ & $\mathrm{C} 3$ & $\mathrm{C} 4$ & $\mathrm{C} 5$ & C6 & $\mathrm{C} 7$ & $\mathrm{C} 8$ & C9 \\
\hline$A_{1}$ & 0.5964 & 0.5056 & 0.5549 & 0.5464 & 0.5821 & 0.5498 & 0.5629 & 0.2693 & 0.4859 \\
\hline$A_{2}$ & 0.4639 & 0.5056 & 0.2466 & 0.4918 & 0.3234 & 0.4276 & 0.2815 & 0.4488 & 0.4859 \\
\hline$A_{3}$ & 0.5302 & 0.2809 & 0.3699 & 0.1639 & 0.2587 & 0.3054 & 0.2815 & 0.3590 & 0.3239 \\
\hline$A_{4}$ & 0.3313 & 0.3933 & 0.5549 & 0.4371 & 0.3881 & 0.4276 & 0.6333 & 0.4488 & 0.4319 \\
\hline$A_{5}$ & 0.1988 & 0.5056 & 0.4316 & 0.4918 & 0.5821 & 0.4886 & 0.3519 & 0.6284 & 0.4859 \\
\hline
\end{tabular}

TABLE VI: WEIGHTED NORMALIZED DECISION MATRIX

\begin{tabular}{cccccccccccc}
\hline$t_{i j}=\bar{r}_{i j} \times W_{j}$ & $\mathrm{C} 1$ & $\mathrm{C} 2$ & $\mathrm{C} 3$ & $\mathrm{C} 4$ & $\mathrm{C} 5$ & $\mathrm{C} 6$ & $\mathrm{C} 7$ & 0.0572 & 0.0356 & 0.0534 & 0.0360 \\
\hline$A_{1}$ & 0.0966 & 0.0723 & 0.0583 & 0.0599 & 0.0235 & 0.0572 & 0.0445 & 0.0178 & 0.0890 & 0.0360 \\
$A_{2}$ & 0.0752 & 0.0723 & 0.0259 & 0.0539 & 0.0130 & 0.0318 & 0.0178 & 0.0712 & 0.0240 \\
$A_{3}$ & 0.0859 & 0.0402 & 0.0388 & 0.0179 & 0.0104 & 0.0318 \\
$A_{4}$ & 0.0538 & 0.0562 & 0.0583 & 0.0479 & 0.0156 & 0.0445 & 0.0400 & 0.0890 & 0.0320 \\
$A_{5}$ & 0.0322 & 0.0723 & 0.0453 & 0.0539 & 0.0235 & 0.0509 & 0.0222 & 0.1247 & 0.0360 \\
\hline
\end{tabular}

TABLE VII: THE EUCLIDEAN DistanCE FROM THE IDEAL POSITIVE AND IDEAL NEGATIVE AS WELL AS PERFORMANCE SCORE

\begin{tabular}{ccccc}
\hline $\begin{array}{l}\text { Various } \\
\begin{array}{l}\text { Decision } \\
\text { Models }\end{array}\end{array}$ & $\mathrm{J}+\mathrm{D}_{\mathrm{IB}}=\sqrt{\sum_{\mathrm{J}=1}^{\mathrm{N}}\left(\mathrm{T}_{\mathrm{IJ}}-\mathrm{T}_{\mathrm{BJ}}\right)^{2},}$ & $\mathrm{~J}^{-} \mathrm{D}_{\mathrm{IW}}=\sqrt{\sum_{\mathrm{J}=1}^{\mathrm{N}}\left(\mathrm{T}_{\mathrm{IJ}}-\mathrm{T}_{\mathrm{WJ}}\right)^{2},}$ & $\mathrm{~S}_{\mathrm{IW}}=\frac{\mathrm{D}_{\mathrm{IW}}}{\mathrm{D}_{\mathrm{IW}}+\mathrm{D}_{\mathrm{IB}}}$ & $\mathrm{RANK}$ \\
\hline$A_{1}$ & 0.0714 & 0.0700 & 0.4950 & 4 \\
$A_{2}$ & 0.0520 & 0.0800 & 0.6061 & 2 \\
$A_{3}$ & 0.0806 & 0.0592 & 0.4235 & 5 \\
$A_{4}$ & 0.0469 & 0.0686 & 0.7598 & 3 \\
$A_{5}$ & 0.0300 & 0.0949 & 1 \\
\hline
\end{tabular}


Table VIII above shows the rating, or the ranking weight done by the expert opinions and stakeholder's preference using the AHP Method. From the table, GI is $19.84 \%$, AI is $16.20 \%$, and PIB $14.3 \%$. Others are TAM $10.98 \%$, FI $10.50 \%, 10.41 \%, 7.41 \%, 6.32 \%$ and $4.03 \%$. The weight of criterion Government Interference having the highest score of 19.84 and hence ranked first among the criteria implies that this is the major factor that constitutes bottleneck to the optimal performance of the refineries. This is in consonance with the lamentations of refinery operators that the poor state of the refinery is because of interference by Government. A situation where Government decides to shutdown refineries, decides when to carry out maintenance, decide on the release of funds and terms and conditions. Decisions on ensuring prompt maintenance of the refineries, most importantly decisions on when to carry out Turn Around Maintenance and who to execute it should not be toyed with by politicians rather by the professionals within the corporation. The result is within an acceptable range of consistency of less than $10 \%$ hence satisfactory.

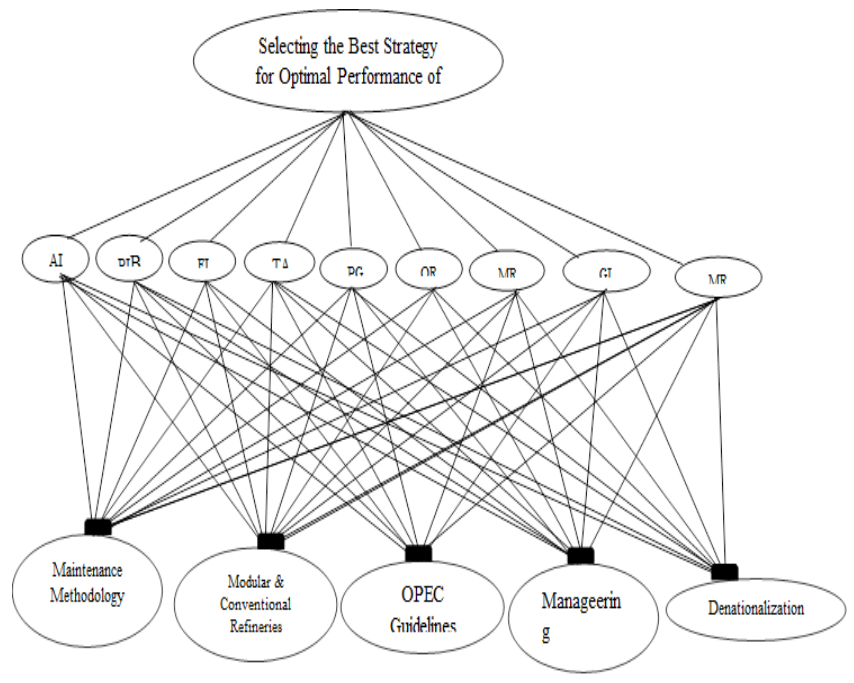

Fig. 3. A multi-criteria model for optimal refinery performance.

\section{CONCLUSION}

The AHP and TOPSIS models have been deployed for analysis in modeling and selecting the alternatives that can help in the optimal performance of the refineries. This study has utilized a collaborative modeling and strategic multiple criteria decision making approach for a decision scenario, where available information, which are subjective are aggregated and simplified. The ranking result can be utilized as strategic information to provide more awareness on the criticality of the bottleneck elements and their attributes to stakeholder and decision makers in the petroleum refining industry. A Policy framework using the Analytic hierarchy process (AHP) with TOPSIS algorithm as an effective tool for supporting refinery optimal performance selection decision can be deduced. The weights of the different criteria have been calculated using the AHP method and for selecting the most desirable model one of well-known MCDM methods namely TOPSIS method has been used. The result from the decision analysis seems logical to support practical situations in terms of the Bottleneck management in Nigeria refinery operations. A decision model, which was developed for the purpose of determining the best alternative from the set of proposed strategies, provides contribution to knowledge.

\section{REFERENCES}

[1] Awolusi O. D. and Onigbinde I.O., Assessment of Critical Success Factors of Business Process Re-Engineering in Nigerian Oil and Gas Industry, International Journal of Empirical Finance, vol. 3, No. 3, pp. 104-120, 2014.

[2] Fan, Z. P., and Feng, B. A multiple attributes decision making method using individual and collaborative attribute data in a fuzzy environment. Information Sciences, vol. 179, pp. 3603-3618, 2009.

[3] Athanasopoulos, G., Riba, C. R., and Athanasopoulou, C. A decision support system for coating selection based on fuzzy logic and multicriteria decision making. Expert Systems with Applications, vol. 36, pp. 10848-10853, 2009.

[4] Saaty, T.L., How to make a decision: the analytic hierarchy process European Journal of Operational Research, vol. 48(1), pp. 9-26, 1990.

[5] Ogedegbe, A.O. (2009): The Nigerian Refineries: History, Problems and Possible Solutions, a lecture delivered at the induction ceremony for new fellows at the Nigerian Academic of Science.

[6] Nigerian National Petroleum Corporation NNPC Statistical Bulletin (2015), The History of Petroleum Development in Nigeria, Lagos.

[7] Ogbuigwe, A. Refining in Nigeria: History, challenges and prospects. Applied Petrochemical Research, vol. 8(4), pp. 181-192, 2018.

[8] Adeleke T. B, Igboanugo A.C. and Chime N.B., A factorial Study of Bottlenecks in Nigerian Petroleum Refineries, European Journal of Engineering Research and Science, EJERS, vol.4, No. 5, 2019.

[9] Goepel, K.D. Implementation of an Online Software Tool for the Analytic Hierarchy Process (AHP-OS). International Journal of the Analytic Hierarchy Process, vol. 10, Issue 3, pp. 469-487, 2018.

[10] Yang, T., and Chou, P., Solving a multi response simulationoptimization problem with discrete variables using a multiple-attribute decision-making method, Mathematics and Computers in Simulation, vol. 68, pp. 9-21, 2005. 